\title{
Inhaled nitric oxide theraphy in preterm infants with severe pulmonary distress syndrome - cases presentation
}

\author{
Mihaela Demetrian', Georgeta Grecu', Andreea Vidru', \\ Andreea Calomfirescu-Avramescu ${ }^{1}$, Alina Ciuca ${ }^{2}$, Anca Panaitescu ${ }^{3}$ \\ ${ }^{1}$ Filantropia Clinical Hospital, Bucharest, Romania \\ 2"Grigore Alexandrescu" Children's Emergency Clinical Hospital, Bucharest, Romania \\ "'Carol Davila" University of Medicine and Pharmacy, Bucharest, Romania
}

\begin{abstract}
Respiratory failure in the premature newborn may be complicated by pulmonary hypertension (PAH) that does not always respond to conventional therapies. Conventional therapy for PAH involves: respiratory support, surfactant administration, sedation and / or muscle relaxation and inotropic agents in the most premature patients.

Our experience in nitric oxide therapy in premature infants under 32 weeks dates back approximately 5 years. There were 7 cases of premature infants with respiratory failure who did not respond to conventional methods of therapy. We will present three case reports with hypoxic respiratory failure and severe pulmonary hypertension that responded favorably to nitric oxide therapy.
\end{abstract}

Keywords: premature infants, pulmonary hypertension, inhaled nitric oxide

\section{BACKGROUND}

Since the introduction of pulmonary surfactant, the rates of mortality caused by respiratory failure in preterm infants significantly decreased [1,2]. Nevertheless, there are cases were oxygenation rate is not improved after surfactant therapy. Preterm infants who are on respiratory support present an elevated risk for developing bronchopulmonary dysplasia (BPD), which has a greater long-term impact.

Regulation of vascular tone in cells is done by nitric oxide (NO) [3]. Nitric oxide is produced from L-arginine by one of the three NO synthases. NO activates guanylate cyclase by binding to its heme component which leads to production of guanosinecyclic monophosphate (cGMP), which is responsible for the vasodilation effect [4]. NO can be combined with inspiratory gases and thereby, be directly carried into peripheral pulmonary alveoli, where it causes local vasodilation.

Pulmonary vascular resistance is adjusted by endogen [5] or exogen [6] NO. Animal experiment models revealed that pulmonary hypertension is decreased by inhalation of nitric oxide. In general, researchers have observed minor or none at all effects over systemic circulation after administration of inhaled nitric oxide (iNO). Studies on adults and on-term newborns have confirmed that iNO produces selective pulmonary vasodilation, reduces pulmonary arterial pressure and improves ventilation/perfusion ratio [7]. In on term newborn infants with hypoxemic respiratory failure, iNO limits the use of ECMO, but does not lower overall mortality [8].

\section{CLINICAL CASES REPORTS}

\section{Case 1}

We describe the case of a premature infant, born at $31+3 / 7$ weeks of gestation with hypoxemic respiratory failure which did not respond to maximal conventional therapy. The pregnancy has been followed up: premature rupture of membranes at 25 weeks of gestation (total time of ruptured membranes: 42 days). 
Corticosteroids prophylaxis, antibiotics and tocolytics were administered. Suspicion of chorioamniotitis and pregnancy of uncertain viability at 31 weeks and 3 days. At birth: previously CPAP (Neopuff) following orotracheal intubation in the delivery room, surfactant administered in the first 30 minutes, initially conventional ventilation: SIMV+PSV FiO2 40-50\% but with rapid deteriorating respiratory function, chest X-ray: right pneumothorax (in the first 60 minutes), right pleural drainage. 6 hours from birth: $\mathrm{SpO} 2-80 \%-$ SIMV+PSV (FiO2 80-90\%), mixed acidosis: $\mathrm{pH} 7.01$, pCO $278 \mathrm{mmHg}$, BB $11 \mathrm{mmol} / \mathrm{l}, \mathrm{EB}$ - $13.4 \mathrm{mmol} / \mathrm{l}$. Oxygenation index (OI), calculated by the formula: $\mathrm{FiO} 2 \times \mathrm{MAP} \times 100 / \mathrm{PaO} 2=55$. A second dose of sur-

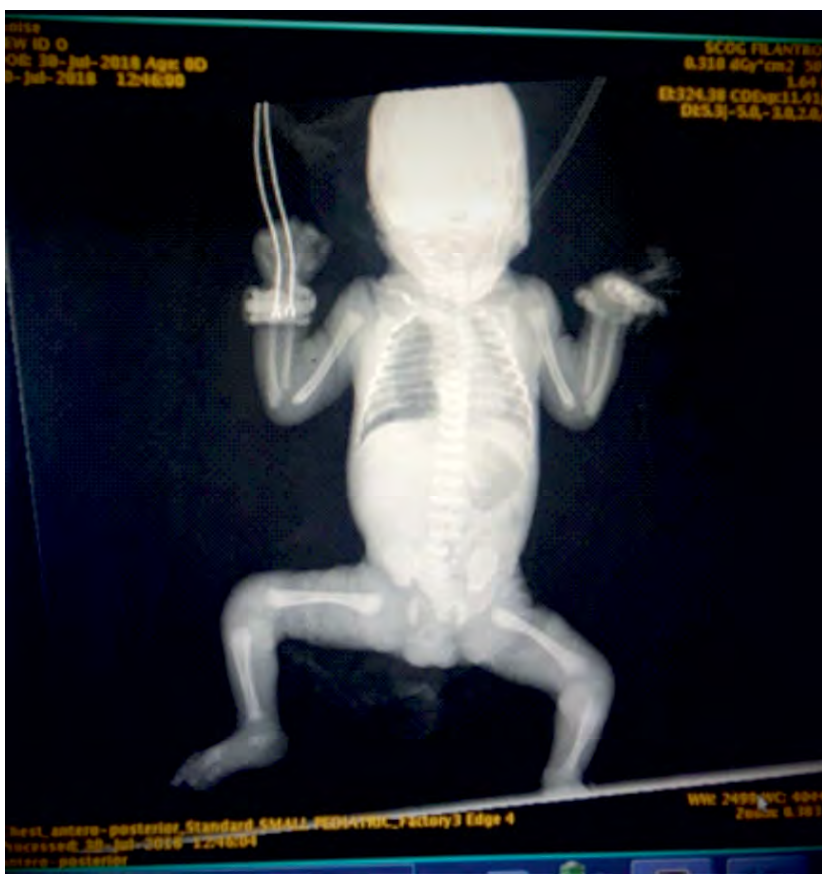

FIGURE 1. Case 1 - Chest X-ray - few hours after birth

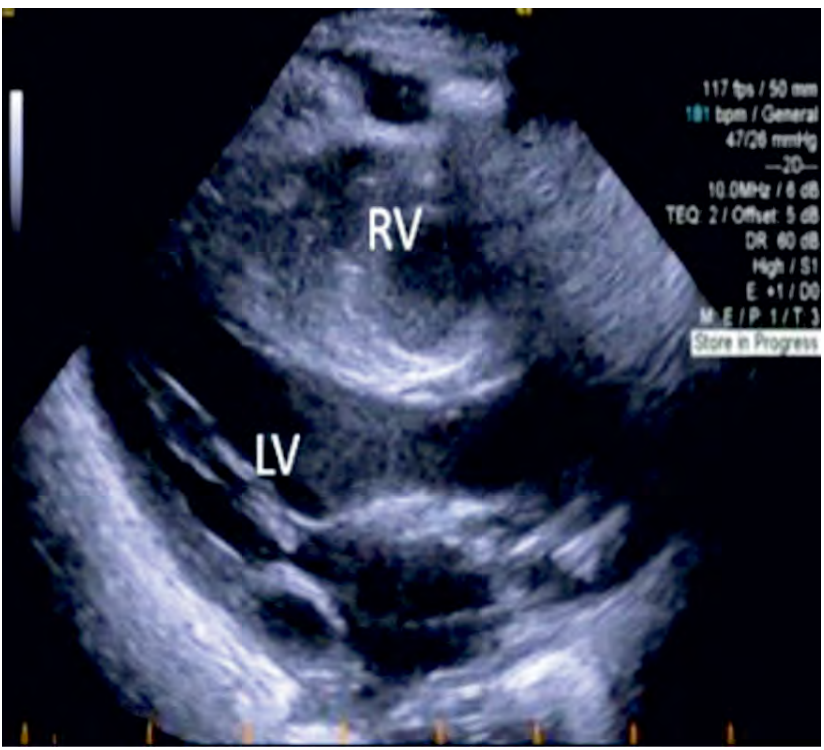

FIGURE 2. Case 1 - Cardiac ultrasound factant is administered; dopamine + dobutamine for cardiocirculatory support. Echocardiography shows: pulmonary hypertension (PAP 70-80 $\mathrm{mmHg}$ ), with right-to-left shunt. At 7 hours of birth iNO therapy is initiated beginning with 15 followed by $20 \mathrm{ppm}$ and ventilation is changed to HFOV; 3-4 hours after administering iNO therapy oxygen saturation is more stable $>90 \%$, FiO2 is gradually decreased (70-60$50 \%$ ) following decrease in iNO administration 18-15-14-10-5 ppm with full cessation after 72 hours of administration. The newborn had remained conventionally ventilated for 4 days following HFNC another 14 days.

\section{Case 2}

We report the case of a female preterm infant, delivered at $30+1$ weeks of gestation by urgent cesarean section because of premature rupture of membranes. She was the first born of a dichorionic diamniotic twin pregnancy (DCDA). At birth: Apgar score 1 min: 5, 5 mins: 8, birth weight: $1380 \mathrm{~g}$. Initially on CPAP, followed by orotracheal intubation. One dose of surfactant was administered, then the newborn was transferred to the neonatal intensive care unit (NICU). At admission: severe general condition, hypotonic-hyporesponsive; oxygen saturation was $93-94 \%$ ( $\mathrm{FiO} 20.45$ ). Blood meconium passed in the first hours after birth; bloody gastric residual aspiration. Blood gas analyses and usual investigations had normal values. Coagulation tests revealed increased prothrombin time and partially activated thromboplastin time. They were corrected by the administration of fresh frozen plasma (FFP).

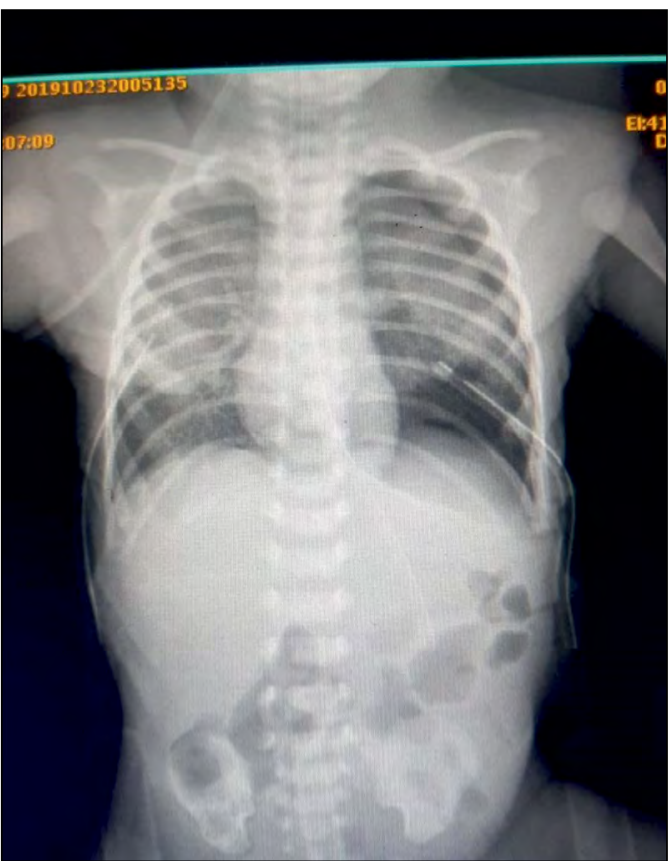

FIGURE 3. Case 2 - Chest X-ray 
In the next few hours, the respiratory function started to deteriorate. Chest $\mathrm{x}$-ray revealed pulmonary effusions, mainly in the left lung and a second dose of surfactant was administered. Head ultrasound was normal. Echocardiography showed patent ductus arteriosus (PDA) and tricuspidian regurgitation (TR) (PAP 40-45 $\mathrm{mmHg}$ ), but treatment with ibuprofen was stalled due to modified coagulation tests. In the second day of life echocardiography was repeated presenting PDA with pulsatile flux. The coagulation tests became normal, allowing the administration of ibuprofen (first dose $10 \mathrm{mg} / \mathrm{kgc}$ ). Large spectrum antibiotics were introduced. In the third day of life, general condition continued to deteriorate. Oxygen saturation was $80 \%$ during SIMV with $\mathrm{FiO} 20.80$ 0.90 . Severe respiratory acidosis $(\mathrm{pH} 6.93, \mathrm{pCO} 275$ $\mathrm{mmHg}$, bicarbonate $11 \mathrm{mmol} / \mathrm{l}$, EB $15.9 \mathrm{mmol} / \mathrm{l})$. A third dose of surfactant and sodium bicarbonate were administered; continuous perfusion with dopamine has been initiated at the same time. Oxygenation index (OI) was 32. Echocardiography revealed severe pulmonary hypertension (PAPs $77-80 \mathrm{mmHg}$ ) with right-to-left shunt. Considering the severe pulmonary hypertension and the critical status, we decided to stop the administration of ibuprofen and to start the iNO therapy. INO began from $10 \mathrm{ppm}$, the newborn being ventilated SIPPV (FiO2 0.95). After one hour iNO was increased to $15 \mathrm{ppm}$ and conventional mechanical ventilation was changed to high frequency oscillation (HFOV). 8 hours later, oxygen saturation and blood gas parameters were improved and we gradually reduced iNO to 13,10 respectively $7.5 \mathrm{ppm}$. At the same time conventional mechanical ventilation was reintroduced and $\mathrm{FiO} 2$ was gradually decreased to 0.50 . After 42 hours of treatment, the echocardiography showed normal pulmonary pressure and PDA with almost full left-to-right shunt. Oxygenation index was 16. INO was gradually lowered, being stopped after 50 hours since the beginning of the treatment. SIMV was continued with $\mathrm{FiO} 2$ gradually decreasing, and after 60 hours since the cessation of iNO, the newborn was extubated. Head ultrasound at $32+5$ weeks of gestation was normal. A follow-up echocardiography has been done, the last one (at 34 weeks of gestation) presented normal pulmonary pressure, without shunts and PDA closed.

\section{Case 3}

We describe the case of preterm infant delivered through cesarean section at $292 / 7$ weeks in vertex presentation after premature rupture of membranes at 26 weeks of gestation. At birth: Apgar score 5/6/6, birth weight 1,400 g. Failure of CPAP due to inefficient respiration. The newborn is intubated in the de-

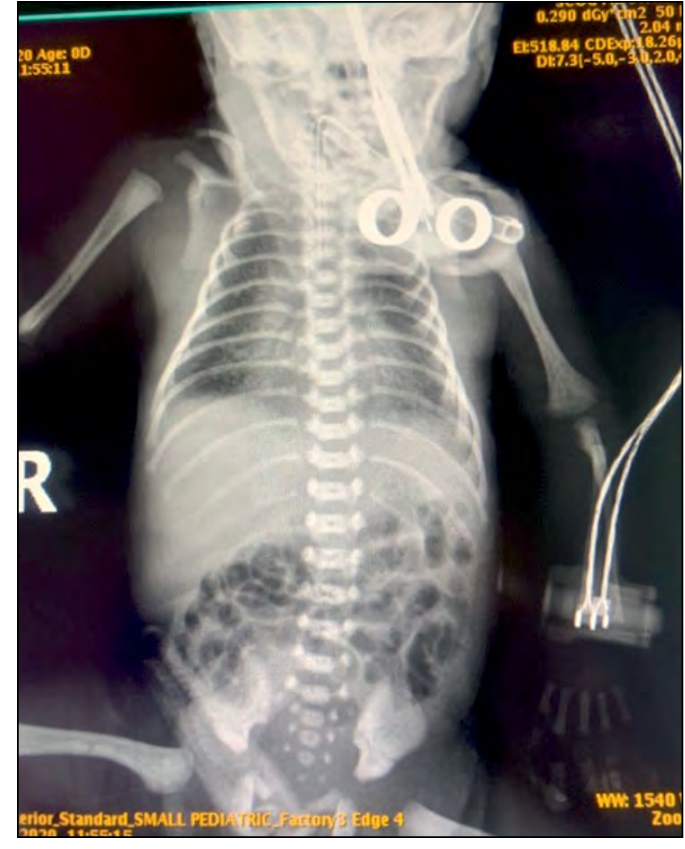

FIGURE 4. Case 3 - Chest X-ray

livery room and afterwards a dose of $200 \mathrm{mg} / \mathrm{kgc}$ of surfactant is administered followed by HFOV ventilation. In the next hours, oxygen saturation is maintained between 89 and $92 \%$ with inspired oxygen concentration of over $60 \%$; hemodynamic instability with noradrenaline and dobutamine support. A second dose of surfactant is administered after 12 hours of life due to frequent desaturations and increased ventilation parameters. No evident amelioration, oxygen saturation stays between $70-80 \%$ at an $80 \%$ oxygen concentration. Chest x-ray shows normal lung expansion to the ninth rib. Echocardiography showed severe pulmonary hypertension (PAPs $80 \mathrm{mmHg}$ ) with rightto-left shunt. Inhaled nitric oxide at $20 \mathrm{ppm}$ simultaneously with HFOV with VG is initiated. Shortly after, oxygen saturation rises to $90 \%$ in approximately two hours. The inspired oxygen concentration is gradually lowered, reaching $40 \%$. INO is administered for 72 hours and after 5 days, the newborn is extubated. He remains oxygen-dependent until 35 weeks of life. The echocardiography done at 32 weeks presented a normal aspect, without any signs of pulmonary hypertension.

\section{DISCUSSIONS}

Although iNO therapy was approved for the treatment of PPHN in on-term and near-term newborns, the efficiency of this therapy in preterm infants with acute hypoxemic respiratory failure is not certain. The results of this treatment seen in on-term newborn infants cannot be extended over preterm infants mainly because of different physiopathological processes 
involved, the selection criteria, and different results. Eligible selection criteria used in iNO studies on on-term newborns have different outcomes in preterm infants where same values of oxygenation index proved to be associated with higher mortality. Although pulmonary arterial pressure is higher in preterm infants with respiratory failure, it rarely inverses the flow through ductus arteriosus. Therefore, the hemodynamic profile of the preterms is different. ECMO is not used in preterm infants because of concerns regarding hemorrhage complications, hence the ECMO criterion cannot be taken into consideration in this case. Experiments using animal models with BPD suggest that a prolonged iNO treatment can modify pulmonary lesions [9]. Inhaled nitric oxide can reduce pulmonary inflammation and improve vascular remodeling in acute preterm lung.

If iNO therapy can decrease the need of ventilatory support then positive effect on the pulmonary lesions can alleviate or even prevent BPD. Nitric oxide generates but also protects from oxidative lesions [10]. Therefore, the effects of iNO therapy over developing lungs need to be closely evaluated before introducing the therapy into clinical practice.

The major concern in preterm infants is the effect of iNO over coagulation. Nitric oxide was proven to increase bleeding time in volunteer adults, and in adults with ARDS [11]. This seems to be cGMPdependent mechanisms; it is presumed that the cGMP in platelets increases while they are transported through the lungs. Preterm infants have a higher risk of developing intraventricular hemorrhage (IVH), which impacts long-term development. Hence, it is important that studies should evaluate the effect of iNO therapy in terms of IVH incidence in preterm infants. A few case reports and case series published before randomized controlled studies (RCT) have shown that in preterm infants with severe respiratory failure, who show no response to conventional treatment, including surfactant administration and highfrequency ventilation, oxygenation ratio can be improved with iNO [12]. Mortality and incidence of IVH were namely researched in these studies.

More recent studies on animal models which focus on the direct effect of iNO in protecting the premature lung against the side effects of hyperoxia [13] and sustaining microvascular growth suggest that there may be possible direct benefits for reducing BPD. Other systematic reviews published about iNO in premature infants are inconclusive.

Inhaled nitric oxide (iNO) was approved for treatment of persistent pulmonary hypertension of the newborn (PPHN) in term and near-term newborns. Its selective vasodilating effect on pulmonary circulation was proven to improve oxygenation and reduce the need of ECMO (extracorporeal membrane oxygenation) [14-20].

On the other hand, its role in hypoxemic respiratory failure due to pulmonary hypertension in preterm newborns remains unclear. There are yet no guidelines or standardized protocols, but some studies have shown that iNO can be used as last resort therapy in preterm newborns with severe pulmonary hypertension who are unresponsive to maximal conventional therapy [21-25].

Different studies have shown that iNO can be used as last resort therapy in preterm infants with severe pulmonary hypertension [8,9]. It seems that the response to iNO is significantly improved upon higher gestational age: newborns aged 29 weeks or older have a higher rate of response to iNO than the ones under 29 weeks [10]. The most recent studies conclude that iNO therapy can improve oxygenation rates in extremely premature newborns with PPHN, but it is not usually recommended and needs to be carefully addressed. Moreover, researchers suggest that $\mathrm{FiO}_{2}>$ 0.65 , PPHN diagnosed by echocardiography and birth weight $>750 \mathrm{~g}$ are independent predictors of iNO therapy with positive results in preterm newborn infants with respiratory distress syndrome (RDS). The cause of pulmonary hypertension in our patients may be difficult to be established, but it is probably a result of the changes in the pulmonary flows (with a higher vasoconstrictive component) secondary to a maternal factor such as PPROM [10]. However, we cannot exclude that ibuprofen administered for PDA closure was one trigger for pulmonary hypertension. Actually, pulmonary hypertension is a rare side effect, but potentially lethal in premature newborns who receive ibuprofen for PDA closure [26,27].

\section{CONCLUSIONS}

Our unit does not have a standard protocol regarding iNO use in preterm newborns. INO therapy is being used as a last resort therapy in preterm newborns with PPHN when maximal conventional therapy has been used (FiO2 0.80-0.90) and failed.

Furthermore, it should be underlined the way in which the general condition of the patients improved when iNO therapy was associated with HFOV, better than with conventional mechanical ventilation, confirming the efficiency of association between iNO and HFOV for treatment of PPHN.

In conclusion, our experience confirms the fact that iNO treatment must be taken into consideration as a last resort therapy in preterm newborns with acute hypoxemic respiratory failure caused by severe pul- 
monary hypertension. Further research and clinical studies should be conducted in order to better determine the real efficiency of this therapy especially in extreme preterm newborns and create standard clinical guidelines and protocols.

Conflict of interest: none declared
Financial support: none declared

\section{REFERENCES}

1. Walther FJ, Benders MJ, Leighton JO. Persistent pulmonary hypertension in premature neonates with severe respiratory distress syndrome. Pediatrics. 1992;90(6):899-904.

2. Soll RF. Prophylactic natural surfactant extract for preventing morbidity and mortality in preterm infants. Cochrane Database Syst Rev. 2000;1997(2):CD000511.

3. Abman SH, Chatfield BA, Hall SL, McMurtry IF. Role of endotheliumderived relaxing factor during transition of pulmonary circulation at birth. American Journal of Physiology 1990;259:H1921-7.

4. Finer NN, Barrington KJ. Nitric oxide therapy for the newborn infant. Seminars in Neonatology 1998;3:127-36.

5. Cornfield DN, Chatfield BA, McQueston JA, McMurtry IF, Abman SH. Effects of birth-related stimuli on L-arginine-dependent pulmonary vasodilation in ovine fetus. American Journal of Physiology 1992; 262:H1474-81.

6. Kinsella JP, McQueston JA, Rosenberg AA, Abman SH. Hemodynamic effects of exogenous nitric oxide in ovine transitional pulmonary circulation. American Journal of Physiology 1992; 263:H875-80.

7. Rossaint R, Falke KJ, Lopez F, Slama K, Pison U, Zapol WM. Inhaled nitric oxide for the adult respiratory distress syndrome. New England Journal of Medicine 1993;328:399-405.

8. Finer NN, Barrington KJ. Nitric oxide for respiratory failure in infants born at or near term. Cochrane Database Syst Rev. 2006; (4):CD000399.

9. Bland RD, Albertine KH, Carlton DP, MacRitchie AJ. Inhaled nitric oxide effects on lung structure and function in chronically ventilated preterm lambs. American Journal of Respiratory and Critical Care Medicine 2005;172:899-906.

10. McAndrew J, Patel RP, Jo H, Cornwell T, Lincoln T, Moellering D, et al. The interplay of nitric oxide and peroxynitrite with signal transduction pathways: implications for disease. Seminars in Perinatology 1997; 21:351-66.

11. Samama CM, Diaby M, Fellahi JL Mdhafar A, Eyraud D, Arock M. Inhibition of platelet aggregation by inhaled nitric oxide in patients with acute respiratory distress syndrome. Anesthesiology 1995;83:56-65.

12. Meurs KP, Rhine WD, Asselin JM, Durand DJ, Premie INO Collaborative Group. Response of premature infants with severe respiratory failure to inhaled nitric oxide. Pediatric Research 1997; 41:271A (Abstract)

13. Bland RD, Albertine KH, Carlton DP, MacRitchie AJ. Inhaled nitric oxide effects on lung structure and function in chronically ventilated preterm lambs. American Journal of Respiratory and Critical Care Medicine 2005;172:899-906.

14. Roberts JD, Polaner DM, Zapol WM, Lang P. Inhaled nitric oxide in persistent pulmonary hypertension of the newborn. Lancet. 1992; 340(8823):818-819.

15. Neonatal Inhaled Nitric Oxide Study Group Inhaled nitric oxide in full-term and nearly full-term infants with hypoxic respiratory failure. N Engl J Med. 1997;336(9):597-604.

16. Roberts JD, Jr, Fineman JR, Morin FC, Shaul PW, Rimar S, Schreiber $M D$, The Inhaled Nitric Oxide Study group et al. Inhaled nitric oxide and persistent pulmonary hypertension of the newborn. $N$ Engl $J$ Med. 1997;336(9):605-610.

17. Al-Alaiyan S, Neiley E. Inhaled nitric oxide in persistent pulmonary hypertension of the newborn refractory to high-frequency ventilation. Crit Care. 1999;3(1):7.

18. Clark RH, Kueser TJ, Walker MW, Southgate WM, Huckaby JL, Perez JA, Roy BJ, Keszler M, Kinsella JP. Low-dose nitric oxide therapy for persistent pulmonary hypertension of the newborn. N Engl J Med. 2000; 342(7):469-474.

19. Barrington KJ, Finer N, Pennaforte T, Altit G. Nitric oxide for respiratory failure in infants born at or near term. Cochrane Database Syst Rev. 2017;1(1):CD000399.

20. Kinsella JP, Cutter GR, Walsh WF, Gerstmann DR, Bose CL, Hart C, Sekar KC, Auten RL, Bhutani VK, Gerdes JS, George TN et al. Early inhaled nitric oxide therapy in premature newborns with respiratory failure. N Engl J Med. 2006;355(4):354-364.

21. Donohue PK, Gilmore MM, Cristofalo E, Wilson RF, Weiner JZ, Lau $\mathrm{BD}$, Robinson KA, Allen MC. Inhaled nitric oxide in preterm infants: a systematic review. Pediatrics. 2011;127(2):e414-e422.

22. Kumar VH, Hutchison AA, Lakshminrusimha S, Morin FC, Wynn RJ, Ryan RM. Characteristics of pulmonary hypertension in preterm neonates. J Perinatol. 2007;27(4):214-219.

23. Barrington KJ, Finer N, Pennaforte T. Inhaled nitric oxide for respiratory failure in preterm infants. Cochrane Database Syst Rev. 2017;1(1):CD000509.

24. Dani C, Corsini I, Cangemi J, Vangi V, Pratesi S. Nitric oxide for the treatment of preterm infants with severe RDS and pulmonary hypertension. Pediatr Pulmonol. 2017;52(11):1461-1468.

25. Baczynski M, Ginty S, Weisz DE, McNamara PJ, Kelly E, Shah P, Jain A. Short-term and long-term outcomes of preterm neonates with acute severe pulmonary hypertension following rescue treatment with inhaled nitric oxide. Arch Dis Child Fetal Neonatal Ed. 2017; 102(6):F508-F514.

26. Gournay V, Savagner C, Thiriez G, Kuster A, Roze JC. Pulmonary hypertension after ibuprofen prophylaxis in very preterm infants. Lancet. 2002;359(9316):1486-1488.

27. Bellini C, Campone F, Serra G. Pulmonary hypertension following L-lysine ibuprofen therapy in a preterm infant with patent ductus arteriosus. Can Med Assoc J. 2006;174(13):1843-1844. 